\title{
Priority directions for the development of the agrarian economy in the context of the digitalization of the agro-industrial complex
}

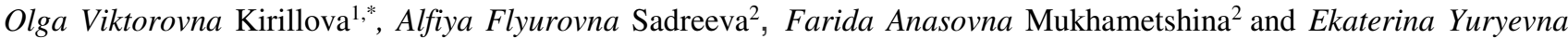 \\ Samysheva ${ }^{2}$ \\ ${ }^{1}$ Kazan State Agrarian University, Kazan, 420015, Russia \\ ${ }^{2}$ Kazan National Research Technical University named after A. N. Tupolev-KAI (KNITU-KAI), Kazan, 420015, Russia
}

\begin{abstract}
The need for digitalization of agriculture is due to several features: many changing factors aimed at the result of production (climatic, biological, etc.); wide dispersal of farms; a significant number of suppliers and buyers of agricultural products, etc. For the agro-industrial complex, the intensification of digitalization processes is associated with an increase in labor productivity at enterprises that use innovative computer technologies. This is necessary for the formation of single information space for the full use of agricultural lands and their effective processing to obtain high-quality products. At the same time, the development of state regulation based on the use of digital technologies remains important. The digitalization of the agrarian economy will increase the competitiveness of Russian agri-food products. The use of information platforms will allow bringing together all the necessary information to improve product quality and increase its sales, considering the specifics of demand. This will reveal weaknesses in the development of the agrarian sector and determine possible solutions, since the analysis of big data will be carried out, the Internet of things will be introduced with the help of state management of agricultural sectors. The article determines that for the development of the agrarian economy in the context of digitalization of the agroindustrial complex, it is necessary to determine possible options for using computer technologies adapted to the conditions of agricultural production; introduce the necessary systems of automated programs and platforms to improve the efficiency of agricultural producers; provide agricultural enterprises with high-speed communication; to determine the main directions of information support for the rational use of land.
\end{abstract}

\section{Introduction}

Currently, digitalization processes occupy an increasingly large part of the life of modern society. The agroindustrial complex cannot stand aside, but there are certain barriers to the digitalization of production and management processes in agriculture. These include:

1. There are no unambiguous standard methods for generating information about production processes and logistics of marketing products in agriculture;

2. Agriculture is not provided with the necessary number of specialists who can work in the conditions of digitalization of production processes, considering the peculiarities of agriculture;

3. There is a high dependence on imported ingredients feed, dietary supplements, etc.

4. The dependence on the adopted international sanctions and trade restrictions in the context of a low level of development of the digital technologies market in Russia is indisputably reflected;
5. The incompleteness of data in the cadastral registration of all land plots that are used in the agroindustrial complex has a negative impact;

6. Agricultural producers and regional authorities are not provided with complete information on the origin of seed and livestock breeding products, on the timing of the beginning and end of tillage, etc .;

7. The agro-industrial complex does not have the necessary specialists who could use information technologies to concentrate information on the state and use of agricultural lands [1].

To effectively eliminate the above barriers, it is necessary to solve a fairly large number of problems that are directly related to:

1. Lack of financing in full of agricultural producers to provide farms with information technology;

2. Unwillingness of highly qualified specialists in the field of information technology to work in the agricultural sector;

3. Existence of an imbalance in the diffusion of digital technologies between cities and rural areas;

Corresponding author: Lesik333@yandex.ru 
4. Imperfection of the regulatory framework for the regulation and development of digital processes in the agro-industrial complex [2].

\section{$2 \quad$ Materials and Methods}

Digital technologies are associated with the use of products such as Big Data, artificial intelligence, control platforms, modern sensors for controlling devices to improve the efficiency of its work. In recent years, a situation has developed that, in the context of ensuring food security, requires the development of exports from the Russian economy, which is practically impossible without the use of innovative technologies. Such technologies will ensure the development of digitalization in agriculture and greatly facilitate the work of farmers. This will undoubtedly lead to a decrease in the costs of agricultural production [3].

The need for digitalization of agriculture is due to several features: many changing factors aimed at the result of production (climatic, biological, etc.); wide dispersal of farms; a significant number of suppliers and buyers of agricultural products, etc. All this requires certainty in planning and forecasting the process of procurement, storage, processing, and marketing of agricultural products [4].

For the agro-industrial complex, the intensification of digitalization processes is associated with an increase in labor productivity at enterprises that use innovative computer technologies. This is necessary for the formation of single information space for the completeness of the use of agricultural lands and their effective processing to obtain high-quality products [5]. At the same time, the development of state regulation based on the use of digital technologies remains important. This is due to the following areas of development of the agricultural economy:

1. Collection and processing of information in the field of agriculture to provide a unified information base to determine digital technologies in the production of agricultural products;

2. the use of the obtained analytical data for the most complete and unambiguous regulation of processes in the agrarian economy when applying the quality control system;

3. Combining the information used for their placement in information systems to effectively manage production processes and circulation to structure data for further use by both farmers and executive authorities. [6].

It should be noted that for effective management of digitalization processes in agriculture, it is necessary to create such computer technologies that would provide the process of state regulation with automated systems. This will make it possible to process large amounts of unstructured data in a single system, i.e., in real-time. Regional ministries and departments have information within their competence; therefore, it is necessary to integrate information into the work of the entire management system of the agro-industrial complex [7, 8].
Using information platforms in agriculture, allowing access to work with large amounts of data, it will be possible to achieve the following results:

1. Using the information on agricultural resources in real-time with the ability to generate analytical data on economic indicators;

2. Planning the effective use of agricultural land;

3. Reducing the cost of agricultural production and, consequently, reducing the cost of production;

4. Increasing the proceeds of agricultural producers;

5. An increase in the number of agro-industrial complex enterprises using digital technologies, which will expand the possibilities for the rapid receipt and processing of information;

6. Attracting highly qualified specialists and increasing the level of wages of rural workers $[9,10]$.

In addition to providing agriculture with the necessary information platforms to ensure digitalization, it is important to adapt the technologies used to the peculiarities of domestic agriculture. It is necessary to create innovative training grounds for testing the applied technologies to choose the most effective one, considering the climatic and climatic characteristics of Russia. To attract specialists to the agro-industrial complex, it is necessary to automate production. This is due to the electronic control of agricultural machinery, special devices, greenhouse complexes, irrigation systems, etc. $[11,12]$.

In general, it is necessary not to forget that the equipment and technologies used in agriculture in Russia are still far behind world standards. Therefore, it remains important to create standardized machines and equipment adapted to the international level. Russia's dependence on foreign technologies and equipment, spare parts is still an urgent problem of ensuring food security and implementing the country's import substitution policy [13].

It is very important to train and improve the qualifications of specialists in the agro-industrial complex in the remote access mode using video consultations, training programs, participation in forums and conferences. This will ensure the exchange of experience not only between domestic enterprises but also to establish relations with foreign partners [14,15]. It will also help in dealing with problems such as long-range, striped, land fragmentation, etc. The effectiveness of monitoring and control of the use of agricultural land is possible only when using the analysis of large amounts of information, which will be generated by information systems.

In the field of secondary specialized and higher education, it is also necessary to introduce innovative standards and new generation programs for training specialists in digital agriculture technologies. Of course, it will take both time and resources, but without specialists who can understand the use of information technologies, the digitalization of the agricultural economy is meaningless [16].

The digitalization of the agricultural economy can create the interaction of complex logistics links, which include agricultural producers, suppliers, large trading 
enterprises, and the state. This will allow not only to provide domestic markets with the necessary products but also to accumulate trade supplies for the export of agricultural products [17].

The digitalization of the agrarian economy will increase the competitiveness of Russian agri-food products. The use of information platforms will allow bringing together all the necessary information to improve product quality and increase its sales, considering the specifics of demand. This will reveal weaknesses in the development of the agrarian sector and determine possible solutions, since the analysis of big data will be carried out, the Internet of things will be introduced with the help of state management of agricultural sectors [18, 19]. Informatization will allow you to interact with participants in the agricultural market, the state, and highly qualified specialists, which will identify the riskiest areas and determine the possibilities of reducing them. A comprehensive analysis of world food markets and identification of domestic export opportunities will become possible.

\section{$3 \quad$ Results}

For the digitalization of agricultural production, it is necessary to increase the level of consumption within the country, the sustainable development of exports of agricultural products, and the use of effective computer technologies to optimize and increase the competitiveness of the Russian economy. An excellent solution would be the mutual exchange of information between agricultural producers about the digital platforms used to select the optimal option for further use by all subjects of the agricultural market. This will ensure the collection and processing of data in a unified format with the integration of information to create a chain of the life cycle of production and sales of products. On the part of the state, a single information center should be created that allows accumulating information that is necessary for the development of a platform for managing specialized equipment and agricultural machinery, and other processes.

It is important to determine the system of indicators for all sectors of agriculture to form a single list of data, with the help of which the necessary information will be collected. This will allow identifying the most effective technologies for the production and sale of agricultural products with feedback functions in the form of advice and recommendations on the use of resource and energysaving technologies. This will be directly related to the development of import-substituting technologies to strengthen the country's food security.

Such work on the digitalization of the agrarian economy will reveal problems in the implementation of information systems, the Internet of things, and big data. Thus, traceability of all factors affecting the implementation of digitalization processes in the agricultural economy will be achieved. It is also necessary to develop a regulatory framework for the implementation and management of digital processes in the agroindustrial complex. At the same time, work on the coordination of the agricultural sector with other sectors of the economy remains important.

The results of such work should be formed databases on the quality of agricultural land used, the selection technologies used, data on the genetic and seed funds of the livestock industry, etc.

We must not forget about the processes of logistics, supply, and marketing of agricultural products, which must also undergo a digitalization process. This will make it possible to build optimal schemes for providing transport logistics systems and exchanging information received from vehicles.

The next stage in the digitalization of the agrarian economy should be the creation of an end-to-end information support system that will ensure the minimization of participants in the supply chain, i.e., will reduce the number of intermediaries in the marketing of agricultural products. The functions of each economic entity in the production chain will be clearly defined, with certain powers and a clear division of labor.

Thus, to ensure the digitalization of the agrarian economy in modern conditions of development, it is necessary to develop the following areas:

1. Based on the developments of Russian scientists, determine possible options for using computer technologies adapted to the conditions of agricultural production;

2. Create jobs that would allow for automated design and automation of processes in the agro-industrial complex for the formation of data on sown areas, peculiarities of crop production, animal husbandry, seed production;

3. Introduce the necessary systems of automated programs and platforms to improve the efficiency of agricultural producers;

4. Ensure the relationship between farms and government agencies using a digital format for the transmission and analysis of information;

5. To form a basis for consulting workers of the agro-industrial complex in real-time, remote format, and the use of digital technologies;

6. Provide agricultural enterprises with high-speed communication;

7. Develop relationships between suppliers and buyers in the agricultural market by using digital technologies for transmitting information about the quantity, quality, and prices of products, production characteristics, etc ;

8. Determine the main directions of information support for the rational use of land, effective zoning of territories, and determination of the production potential of agricultural land used;

9. To form ways and methods, digital technologies, and means by which digital monitoring of lands, data on animals and plants, soil, breeding, and genetic material will be carried out.

10. Determine the possibilities of digitalization of information on potential aggregate supply and demand in agricultural markets;

Ensure the formation and updating of a digital platform containing information on lending and insurance 
of domestic agricultural producers to simplify the workflow and timely use of concessional lending.

\section{Conclusion}

In conclusion, we would like to note that in modern conditions, the development and implementation of digitalization processes in the agricultural economy is a production necessity. But for its successful implementation, it is necessary to carry out the necessary series of measures, which will make it possible to determine the most effective areas, digital technologies, information models.

This is due, first of all, to the introduction of the necessary systems of automated programs and platforms, which make it possible to increase the efficiency of the work of agricultural producers; the creation of jobs that would allow for automated design and automation of processes in the agro-industrial complex for the formation of data on sown areas, peculiarities of crop production, animal husbandry, seed production; development of relationships between suppliers and buyers in the agricultural market through the use of digital technologies for transmitting information about the quantity, quality and prices of products, production characteristics and the formation of methods and methods, digital technologies and means by which digital monitoring of lands, animal data will be carried out and plants, soil, breeding, and genetic material. Work on the digitalization of the agrarian economy will reveal problems in the implementation of information systems, the Internet of things, and big data. Thus, traceability of all factors affecting the implementation of digitalization processes in the agricultural economy will be achieved. It is also necessary to develop a regulatory framework for the implementation and management of digital processes in the agro-industrial complex.

\section{References}

1. E.F. Amirova, O.Y. Voronkova, K.A. Pyurveeva, M.A. Shatalov, T.A. Panteleeva, O.A. Sorokina, Functioning of agroindustrial complex in the conditions of digital economy, International Journal of Mechanical Engineering and Technology, 9, 12 (2018)

2. E.F. Amirova, I.N. Safiullin, L.G. Ibragimov, N.V. Karpova, State regulation of the agricultural sector in the context of sanctions and the development of the digital economy, Bulletin of Kazan State Agrarian University, 14, 3 (2019)

3. P.B. Akmarov, M.K. Gazetdinov, O.P. Knyazeva, State and main directions of development of the digital economy in agriculture in Russia, Bulletin of Kazan State Agrarian University, 1, 106-111 (2019)

4. M.F. Amirov, Influence of microelements and mineral fertilizers on yield and grain quality of spring wheat, Bulletin of Kazan SAU, 4, 5-8 (2017)

5. O.V. Bakhareva, The concept of territorial development of the region: real vs. digital infrastructure, Management of Economic Systems, 1, 37 (2019)

6. O.V. Bakhareva, Infrastructure in the Region: LongTerm Investments of Institutional Investors in Russia, Journal of Advanced Research in Law and Economics, 3, 488-503 (2015)

7. M.K. Gazetdinov, O.S. Semicheva, S.M. Gazetdinov, Social and Labor Aspects of the Economic Mechanism of Rural Development, Rural machinery and equipment, 10, 36-39 (2017)

8. M.K. Gazetdinov, O.S. Semicheva, A.R. Zakirova, A.R. Yusupova, Formation of management information in crop production in the context of digitalization, Modern achievements of agricultural science, 521-531 (2020)

9. F.F. Gatina, A.R. Artamonycheva, Investment activity of the Republic of Tatarstan in the agricultural sector of the economy, Economics of Agricultural and Processing Enterprises, 7, 50-52 (2008)

10. E.Y. Ermakova, Y.F. Korotkov, M.G. Kuznetsov, N.A. Nikolaev, Cleaning contaminated water by gravity flotation, Chemical and Petroleum Engineering, 1-2, 46 (2010)

11. A.R. Zakirova, Topical issues of organizing management accounting in agricultural organizations in accordance with international financial reporting standards, Bulletin of Kazan State Agrarian University, 5, 4 (2010)

12. O.V. Kirillova, E.F. Amirova, M.G. Kuznetsov, G.A. Valeeva, G.P. Zakharova, Innovative directions of agricultural development aimed at ensuring food security in Russia, BIO Web of Conferences, 00068 (2020).

13. O.V. Kirillova, The main issues of ensuring the country's food security, in: The role of socioeconomic science in ensuring the country's food security. International scientific and practical conference (Kazan State Agrarian University) pp. 5153 (2018)

14. M.G. Kuznetsov, Processing of vegetable raw materials, in: 2nd International scientific-practical conference Development of the agro-industrial complex and rural areas in the context of economic modernization, pp. 111-114 (2020)

15. D.I. Fayzrakhmanov, L.R. Shagivaliev, F.T. Nezhmetdinova, Improving the efficiency of staffing the agro-industrial complex in the Republic of Tatarstan based on the cluster approach, Bulletin of Kazan State Agrarian University, 2(1) (2014)

16. M.F. Amirov, I.R. Valeev, A.R. Valiev, V.P. Vladimirov, I.K. Gabdrakhmanov et al., Regulations for the development of technological maps in crop production, The farming system of the Republic of Tatarstan, 3, 281-283 (2014)

17. A.K. Subaeva, L.M. Mavlieva, N.R. Alexandrova, M.M. Nizamutdinov, Technical modernization of the land reclamation system as a reserve for increasing 
the efficiency of agriculture, Bulletin of Kazan State Agrarian University, 12, 124-127 (2017)

18. D.I. Fayzrakhmanov, S.M. Gazetdinov, Problems of Small and Medium Business Development in the Agrarian Sector of the Economy, Bulletin of Kazan State Agrarian University, 9, 38-42 (2014)
19. A.R. Yusupova, Digital transformation of the agroindustrial complex, in: 2nd International Scientific and Practical Conference (Kazan State Agrarian University) pp. 189-191 (2020) 